\title{
HUBUNGAN PENGETAHUAN DENGAN SIKAP ISTRI DALAM PEMILIHAN KONTRASEPSI ALAMIAH METODE OVULASI BILLINGS (MOB) DI PUSKESMAS SUNGAI RAYA DALAM TAHUN 2017
}

\author{
Elise Putri ${ }^{1}$, Megalina Limoy ${ }^{2}$
}

\author{
Akademi Kebidanan Panca Bhakti Pontianak
}

Email korespondensi: akbidpbpontianak@gmail.com

\begin{abstract}
Abstrak
Metode ovulasi billings dikembangkan pada tahun 1950-an oleh dua orang dokter warga negara Australia, yaitu Drs.Evelyn dan John Billings. Di dunia, angka pengguna Metode Ovulasi Billings hanya 3,4\% dari seluruh pasangan yang sudah menikah. Di Indonesia angka pengguna metode ovulasi billings sendiri belum diketahui sedangkan angka pengguna metode alamiah adalah $0,4 \%$ dari seluruh akseptor KB. Tujuan penelitian ini adalah untuk mengetahui hubungan antara pengetahuan dengan sikap istri dalam pemilihan Metode Ovulasi Billings di Puskesmas Sungai Raya Dalam. Dalam penelitian ini menggunakan metode analitik korelasi dengan pendekatan cross sectional. Teknik sampling yang digunakan adalah accidentally sampling dengan jumlah populasi 124 orang dan jumlah sampel sebanyak 31 orang yaitu seluruh akseptor KB yang hadir di Puskesmas Sungai Raya Dalam. Dari hasil penelitian menunjukkan bahwa sebagian besar dari responden yaitu 20 orang (65\%) berpengetahuan kurang dan tidak memilih Metode Ovulasi Billings. Sedangkan sangat sedikit responden yaitu 1 orang (3\%) berpengetahuan baik dan memilih Metode Ovulasi Billings. Dari hasil uji statistic yang telah dilakukan didapatkan x2 hitung $(6,55)>$ dari x2 tabel $(5,99)$ sehingga ada hubungan yang signifikan antara pengetahuan dengan sikap istri dalam pemilihan kontrasepsi alamiah metode ovulasi billings di Puskesmas Sungai Raya Dalam Tahun 2017. Kesimpulan peneliti yaitu pengetahuan akseptor tentang Metode Ovulasi Billings perlu ditingkatkan. Puskesmas bisa melakukan sosialisasi tentang Metode Ovulasi Billings agar tenaga kesehatan dapat memberikan penjelasan yang lebih luas tentang Metode Ovulasi Billings kepada seluruh akseptor KB.
\end{abstract}

Kata Kunci: Pengetahuan, Sikap, Istri, Metode Ovulasi Billings

\section{Pendahuluan}

Keluarga berencana adalah tindakan yang membantu individu atau pasangan suami istri untuk mendapatkan objetif-objektif tertentu, menghindari kelahiran yang tidak diinginkan, mendapatkan kelahiran yang memang diinginkan, mengatur interval diantara kehamilan, mengontrol waktu saat kelahiran dalam hubungan dengan suami istri dan menentukan jumlah anak dalam keluarga (BKKBN, 2009).

Metode keluarga berencana dibagi menjadi dua yaitu metode alami dan modern. Metode modern diantaranya yaitu kontrasepsi hormonal, alat kontrasepsi bawah kulit, alat kontrasepsi dalam rahim, kontrasepsi mantap,

\footnotetext{
${ }^{1}$ Dosen Akademi Kebidanan Panca Bhakti Pontianak

${ }^{2}$ Dosen Akademi Kebidanan Panca Bhakti Pontianak
}

dan vasektomi. Sedangkan metode alamiah yaitu metode kalender, metode suhu basal, metode lendir serviks dan metode symptotermal.

\section{Menurut data World Health Organization} (2015) penggunaan kontrasepsi telah meningkat di banyak bagian dunia, terutama di Asia dan Amerika Latin, tetapi terus menjadi rendah di sub-Sahara Afrika. Secara global, penggunaan kontrasepsi modern telah meningkat sedikit, dari 54\% pada tahun 1990 menjadi 57,4\% pada tahun 2015.

Sedangkan pada data Riskesdas 2013 menunjukkan bahwa pada wanita usia 15-49 tahun dengan status kawin sebesar 59,3\% 
menggunakan KB modern (implan, MOW, MOP, IUD, kondom, suntikan, pil), 0,4\% menggunakan metode $\mathrm{KB}$ tradisional (menyusui/MAL, pantang berkala/kalender, senggama terputus, dll) 2,7\% pernah melakukan $\mathrm{KB}$, dan 15,5\% tidak pernah melakukan KB.

Salah satu metode kontrasepsi alamiah yaitu metode ovulasi billings dikembangkan pada tahun 1950-an oleh dua orang dokter warga negara Australia, yaitu Drs.Evelyn dan John Billings, kemudian diperkenalkan ke Amerika Serikat pada awal tahun 1970-an (Sulistyawati, 2011).

Metode Ovulasi Billings didasarkan pada pengenalan terhadap perubahan lendir serviks selama siklus menstruasi yang menggambarkan masa subur dalam siklus dan waktu fertilitas maksimal dalam masa subur (Sulistyawati, 2011).

Berdasarkan data BKKBN (2016), persentase peserta $\mathrm{KB}$ di Indonesia pada tahun 2016 sebesar 33,72\%. Angka ini lebih rendah dibandingkan capaian tahun 2015 sebesar $38,75 \%$. Tiga provinsi yang memiliki persentase tertinggi yaitu Aceh (23,3\%), Kalimantan Barat $(17,8 \%)$, dan Sumatera Selatan $(16,2 \%)$.

Tingkat pengetahuan ibu tentang metode kontrasepsi yang diperoleh dari pemberian informasi yang akurat dan tidak bias dapat mempengaruhi keputusan ibu untuk memilih dan menggunakan metode kontrasepsi (Pendit, 2007).

Selain itu, di Indonesia ketidaksetaraan gender masih sering ditemukan sehingga menyebabkan rendahnya kesertaan ber-KB pada laki-laki dan perempuan tidak bisa memilih metode kontrasepsi yang diinginkan (Marmi, 2015)

Provinsi Kalimantan Barat berada diatas rata-rata nasional dengan penggunaan alat kontrasepsi (alkon) modern sebanyak 65,42\%. Pasangan usia subur di provinsi ini yang menggunakan kontrasepsi alamiah sebanyak $0,34 \%$, sehingga pasangan usia subur yang berKB secara keseluruhan di provinsi ini sebanyak $65,76 \%$ dan pasangan usia subur yang tidak berKB di Kalimantan Barat sebanyak 34,24\% (Survei Sosial Ekonomi Nasional, 2015).

Berdasarkan penelitian yang dilakukan oleh Erniyawati (2007) pada ibu-ibu akseptor KB di 4 taman kanak-kanak kecamatan Sleman didapatkan bahwa 50\% dari 100 responden kurang mengetahui tentang metode kontrasepsi alamiah walaupun sebenarnya mereka melakukan kontrasepsi tersebut.

Hasil dari penelitian yang telah dilakukan oleh Sari (2008) terhadap masyarakat disekitar kampus IPB menunjukkan bahwa 19 dari 20 orang responden yang diwawancarai belum mengetahui tentang Metode Ovulasi Billings. Padahal metode ini sangat berpotensi untuk dijadikan sebagai metode alternatif keluarga berencana.

Dari studi pendahuluan yang dilakukan peneliti di Puskesmas Sungai Raya Dalam didapatkan data yaitu sebanyak 5289 peserta KB aktif selama tahun 2016. Sedangkan pada bulan Januari sampai dengan Maret 2017 terdapat sebanyak 124 akseptor. Kemudian peneliti melakukan wawancara dengan akseptor KB tentang pengertian kontrasepsi alamiah, jenis kontrasepsi alamiah, pengertian metode ovulasi billings, keuntungan dan kerugian 
metode ovulasi billings, serta cara kerja metode ovulasi billings pada 10 responden dengan kriteria seorang istri akseptor $\mathrm{KB}$, bisa baca tulis, dan bersedia menjadi responden berpedoman pada instrumen yang peneliti buat ditemukan bahwa 8 responden tidak mengetahui tentang Metode Ovulasi Billings, 1 responden mengetahui tentang metode ovulasi billings dan kekurangan kerugiannya tetapi tidak mengetahui cara kerjanya, sedangkan 1 responden lainnya mengetahui tentang Metode Ovulasi Billings beserta kekurangan kerugian dan cara kerjanya.

\section{Metode}

Penelitian ini menggunakan jenis penelitian deskriptif korelasional dengan pendekatan cross sectional. Penelitian dilaksanakan pada bulan April hingga Mei 2017 di Puskesmas Sungai Raya Dalam. Populasi penelitian yaitu akseptor KB di Puskesmas Sungai Raya Dalam sebanyak 124 orang. Peneliti menggunakan $25 \%$ populasi menjadi sampel sebanyak 31 orang. Pengumpulan data menggunakan kuesioner kemudian diolah dan dianalisis menggunakan analisis univariat serta analisis bivariat menggunakan uji chi square.

\section{Hasil dan Pembahasan}

Tabel 1. Karakteristik Responden

\begin{tabular}{lcc}
\hline \multicolumn{1}{c}{ Karakteristik } & $\mathrm{n}$ & $\%$ \\
\hline Pengetahuan & & \\
Baik & 5 & 16 \\
Cukup & 5 & 16 \\
Kurang & 21 & 68 \\
Sikap & & \\
Memilih & 5 & 16 \\
Tidak Memilih & 26 & 84 \\
\hline
\end{tabular}

Dilihat dari tabel 1 diatas dapat diketahui bahwa dari 31 responden, sebagian besar responden yaitu 21 orang (68\%) berpengetahuan kurang dan sangat sedikit dari responden yaitu 5 orang (16\%) berpengetahuan cukup dan baik tentang Metode Ovulasi Billings. Berdasarkan tabel 1 diatas diketahui bahwa hampir seluruh dari responden yaitu 26 orang (84\%) memiliki sikap tidak memilih terhadap Metode Ovulasi Billings.

Tabel 2. Analisis Hubungan Pengetahuan dengan Sikap Istri dalam Pemilihan Kontrasepsi Metode Ovulasi Billings

\begin{tabular}{|c|c|c|c|c|c|c|c|c|}
\hline \multirow{3}{*}{ Variabel } & \multicolumn{4}{|c|}{ Sikap } & \multirow{2}{*}{\multicolumn{2}{|c|}{ Total }} & \multirow{3}{*}{$\begin{array}{l}\text { OR } \\
95 \%\end{array}$} & \multirow{3}{*}{ P Value } \\
\hline & \multicolumn{2}{|c|}{ Memilih } & \multicolumn{2}{|c|}{ Tidak Memilih } & & & & \\
\hline & $\mathrm{n}$ & $\%$ & $\mathrm{n}$ & $\%$ & $\mathrm{n}$ & $\%$ & & \\
\hline Baik & 1 & 20 & 4 & 80 & 5 & 100 & & \\
\hline Pengetahuan Cukup & 3 & 60 & 2 & 40 & 5 & 100 & 0,189 & 0,004 \\
\hline Kurang & 1 & 4,75 & 29 & 95,23 & 21 & 100 & & \\
\hline
\end{tabular}


Dari tabel diatas dapat disimpulkan bahwa sebagian besar dari responden yaitu 21 orang $(68 \%)$ berpengetahuan kurang tentang Metode Ovulasi Billings. Dan diantaranya hampir seluruh responden yang berpengetahuan kurang yaitu 20 orang $(95,23 \%)$ tidak memilih Metode Ovulasi Billings sedangkan sangat sedikit dari responden yang berpengetahuan kurang yaitu 1 orang $(4,76 \%)$ memilih Metode Ovulasi Billings.

Dari hasil penelitian menunjukkan bahwa sebagian besar responden memiliki pengetahuan yang kurang tentang metode ovulasi billings yaitu 21 responden (68\%). Sangat sedikit dari responden yaitu 5 orang responden (16\%) berpengetahuan cukup dan 5 orang (16\%) lainnya berpengetahuan baik. $\mathrm{P}$ value yang diperoleh adalah 0,004 yang berarti terdapat hubungan yang signifikan antara pengetahuan dan sikap.

Berdasarkan data dari kuisioner yang telah diteliti hal ini disebabkan oleh tingkat pendidikan responden sebagian besar menengah kebawah sehingga pengetahuan yang didapatkan responden tentang Metode Ovulasi Billings masih kurang.

Terdapat beberapa teori dari para ahli yang menyebutkan bahwa pendidikan mempengaruhi pengetahuan. Menurut Notoatmodjo (2010) pendidikan mempengaruhi pengetahuan karena pendidikan adalah suatu usaha mengembangkan kepribadian dan kemampuan didalam dan diluar sekolah dan berlangsung seumur hidup. Pengetahuan sangat erat kaitannya dengan pendidikan dimana diharapkan seseorang dengan pendidikan tinggi maka orang tersebut akan semakin luas pula pengetahuannya.

Sedangkan menurut Mubarak (2012) pendidikan berarti bimbingan yang diberikan seseorang pada orang lain terhadap sesuatu hal agar mereka dapat memahami. Tidak dapat dipungkiri bahwa makin tinggi pendidikan seseorang semakin mudah pula mereka menerima informasi, dan pada akhirnya makin banyak pula pengetahuan yang dimilikinya.

Dari hasil penelitian menunjukkan bahwa sangat sedikit dari responden yaitu 5 orang $(16 \%)$ memiliki sikap memilih terhadap metode ovulasi billings sedangkan hampir seluruh dari responden yaitu 26 orang (89\%) memiliki sikap tidak memilih terhadap metode ovulasi billings.

Hal tersebut berdasarkan pengisian kuesioner yang telah diajukan kepada responden sebanyak 10 pertanyaan yang mencakup sikap responden terhadap metode ovulasi billings baik sikap positif maupun negatif. Menurut Azwar (1995) dalam buku Maulana (2009), pembentukan sikap dipengaruhi beberapa faktor, yaitu pengalaman pribadi, media massa, institusi atau lembaga pendidikan dan lembaga agama, dan faktor emosi dalam diri individu.

Sementara itu menurut Krech dkk, pembentukan dan perubahan sikap dapat disebabkan oleh suatu interaksi kelompok dan situasi komunikasi media. Semua kejadian tersebut mendapatkan pengalaman dan pada akhirnya akan membentuk keyakinan, perasaan serta kecenderungan berperilaku (Maulana, 2009).

Dari hasil penelitian menunjukkan bahwa sangat sedikit dari responden yaitu 5 orang 
(16\%) berpengetahuan baik tentang Metode Ovulasi Billings. Dari 5 orang tersebut, sebagian kecil dari responden yang berpengetahuan baik tentang Metode Ovulasi Billings yaitu 1 orang (20\%) memilih Metode Ovulasi Billings dan hampir seluruh responden yang berpengetahuan baik yaitu 4 orang ( $80 \%$ ) tidak memilih Metode Ovulasi Billings.

Untuk responden yang berpengetahuan cukup tentang Metode Ovulasi Billings terdapat sebagian kecil dari responden yaitu 5 orang (16\%). Diantaranya yaitu sebagian besar dari responden yang berpengetahuan cukup adalah 3 orang (60\%) memilih Metode Ovulasi Billings dan sebagian dari responden yang berpengetahuan cukup yaitu 2 orang (40\%) tidak memilih Metode Ovulasi Billings.

Selanjutnya sebagian besar dari responden yaitu 21 orang (68\%) berpengetahuan kurang tentang Metode Ovulasi Billings. Diantaranya hampir seluruh responden yang berpengetahuan kurang yaitu 20 orang (95,23\%) tidak memilih Metode Ovulasi Billings dan sangat sedikit dari responden yang berpengetahuan kurang yaitu 1 orang $(4,76 \%)$ memilih Metode Ovulasi Billings.

Menurut Mubarak (2012) semakin rendah pengetahuan seseorang maka akan menghambat perkembangan sikap seseorang terhadap penerimaan, informasi, dan nilai-nilai yang perlu diperkenalkan. Pernyataan tersebut berkaitan dengan hasil yang telah didapatkan pada penelitian ini yaitu sebagian besar responden $(68 \%)$ memiliki pengetahuan yang kurang tentang Metode Ovulasi Billings sehingga mempengaruhi sikap responden terhadap pemilihan Metode Ovulasi Billings dimana hampir seluruh responden (84\%) tidak memilih Metode Ovulasi Billings.

Hal tersebut sejalan dengan penelitian yang telah dilakukan sebelumnya oleh Maria Erni Aba pada tahun 2016 menggunakan metode penelitian deskriptif dengan judul "Gambaran Pengetahuan dan Sikap Pasangan Usia Subur dalam Pemilihan KB Alamiah Metode Ovulasi Billings di RS St.Elisabeth Kabupaten Sambas 2016". Hasil penelitian didapatkan yaitu sebagian dari responden tepatnya 31 pasangan usia subur (58\%) memiliki pengetahuan yang kurang dan sangat sedikit dari responden yaitu 10 pasangan usia subur (19\%) memiliki pengetahuan yang baik sedangkan 12 pasangan usia subur (23\%) memiliki pengetahuan yang cukup tentang Metode Ovulasi Billings.

Berdasarkan penelitian yang dilakukan oleh Dwi Erniyawati tahun 2015 pada ibu-ibu akseptor kb di 4 taman kanak-kanak kecamatan Sleman didapatkan bahwa 50\% dari 100 responden kurang mengetahui tentang metode kontrasepsi alamiah walaupun sebenarnya mereka melakukan kontrasepsi tersebut.

Hasil dari penelitian yang telah dilakukan oleh Wahyu Eka Ningsih pada tahun 2008 terhadap masyarakat disekitar kampus IPB menunjukkan bahwa 19 dari 20 orang responden yang diwawancarai belum mengetahui tentang Metode Ovulasi Billings. Padahal metode ini sangat berpotensi untuk dijadikan sebagai metode alternatif keluarga berencana.

Menurut Mubarak (2012), semakin rendah pengetahuan seseorang maka akan menghambat perkembangan sikap seseorang 
terhadap penerimaan, informasi, dan nilai-nilai yang perlu diperkenalkan. Pernyataan tersebut berkaitan dengan hasil yang telah didapatkan pada penelitian ini yaitu semakin rendah pengetahuan responden tentang Metode Ovulasi Billings maka akan semakin mempengaruhi sikap responden dalam memilih metode kontrasepsi tersebut.

\section{Kesimpulan}

Berdasarkan hasil penelitian yang telah dilakukan, maka dapat disimpulkan bahwa ada hubungan antara pengetahuan dengan sikap dalam pemilihan kontrasepsi alamiah metode ovulasi billings.

\section{Daftar Pustaka}

Alimul, Aziz. 2014. Metode Penelitian Kebidanan \& Teknik Analisis Data. Jakarta: Salemba

Arikunto, Suharsimi. 2010. Prosedur Penelitian Suatu Pendekatan Praktik. Jakarta: Rineka Cipta

2011 Prosedur Penelitian Suatu Pendekatan Praktik. Jakarta: Rineka Cipta

Azwar, Saifuddin. 2011. Sikap ManusiaTeori Dan Pengukurannya. Yogyakarta: PustakaPelajar

Billings, Evelyn.L. 2007. Mengenal Metode Ovulasi Billings. Yogyakarta: PT. Kanisius

BKKBN. 2009. Profil BKKBN Tahun 2009.https://www.bkkbn.go.id/ diakses: 12 Maret 2017, 20.10 WIB

2016. Profil BKKBN Tahun 2016.https://www.bkkbn.go.id/ diakses: 16 Maret 2017, 19.35 WIB
2017. Visi dan Misi Keluarga

Berencana.https://www.bkkbn.go.id/ diakses: 19 Maret 2017, 18.20 WIB

Depkes RI. 2014. Riset Kesehatan Dasar (Riskesdas) $2013-$ Kemenkes. www.depkes.go.id diakses: 14 Maret 2017, 11.20 WIB

Everett, Suzanne. 2008. Kontrasepsi \& Kesehatan Seksual Reproduktif. Jakarta: EGC

Erniyawati, Dwi. 2007. Pengetahuan dan Motivasi Tentang Kontrasepsi Pada Akseptor KB Di 4 Taman Kanak- Kanak Di Kecamatan Sleman. https://repository.usd.ac.id/2804/2/9981 14224_Full.pdf, diakses: 01 Maret, 09.20 WIB

Fitriani, Sinta. 2011. Promosi Kesehatan. Yogyakarta: GRAHA ILMU

Handayani, Sri. 2010. Pelayanan Keluarga Berencana. Yogyakarta: Pustaka Rihama

Irianto, Koes. 2014. Pelayanan Keluarga Berencana. Bandung: ALFABETA

Kartadibata, H. Sunaryo. (2010). Pedoman Karya Tulis Ilmiah. Bandung: Universitas Pendidikan Indonesia

Klein, Paul \& Team KBA. 2010. Keluarga Berencana Alamiah? Mengapa Tidak. Malang: Dioma

Marmi. 2015. Kesehatan Reproduksi. Yogyakarta: Pustaka Pelajar

Maulana, Heri D.J. 2007. Promosi Kesehatan. Jakarta: EGC

Jakarta: EGC

2009. Promosi Kesehatan.

2013. Promosi Kesehatan. Jakarta: EGC

Mubarak, Wahit Iqbal, dkk. 2012. Promosi Kesehatan: Sebuah Pengantar Proses Belajar Mengajar dalam Pendidikan. Yogyakarta: Candi Gebang Permai 
Notoatmodjo, Soekidjo. 2010. Metodologi Penelitian Kesehatan. Jakarta: Rineka Cipta

2012. Metodologi Penelitian Kesehatan. Jakarta: Rineka Cipta

Pendit, B.U. 2007. Ragam Metode Kontrasepsi. Jakarta: EGC

Pinem, Saroha. 2009. Kesehatan Reproduksi dan Kontrasepsi. Jakarta: CV. Trans Info Media

Proverawati, Atikah dkk. 2010. Panduan Memilih Kontrasepsi. Yogyakarta: Nuha Medika

Riwidikdo, Handoko. 2008. Statistik Kesehatan. Jogjakarta: Mitra Cendika

Sabri, Luknis dan Sutanto Priyo Hastono. 2014. Statistik Kesehatan. Jakarta: Rajawali Pers

Sari, Eka Wahyu. 2008. "OB Ovulasi Billings Masuk Desa": Program Pengenalan Metode Alternatif Keluarga Berencana Di Kelurahan Balumbang Jaya. http://repository.ipb.ac.id/jspui/bitst ream/123456789/6/WahyuEkaSari PKMGT.doc diakses: 01 Maret 2017,08.35 WIB

Sugiyono. 2011. Statistika untuk Penelitian. Bandung: ALFABETA

2012. Statistika untuk Penelitian. Bandung: ALFABETA 2014. Statistika untuk Penelitian. Bandung: ALFABETA

Sulistyawati, Ari. 2011. Pelayanan Keluarga Berencana. Jakarta: Salemba Medika

Survei Sosial Ekonomi Nasional, 2015. Analisis Data Kependudukan dan KB Hasil Susenas 2015. kalbar.bkkbn.go.id diakses: 28 Februari 2017, 14.00

Susila dan Suyanto. 2014. Metodologi Penelitian Cross Sectional. Klaten: BOSSSCRIPT
Suyanto, dkk. 2014. Metodologi Penelitian Kesehatan dan Kedokteran. Yogyakarta: Bursa Ilmu

Uliyah, Mar'atul. 2010. Panduan Aman dan Sehat Memilih Alat KB. Yogyakarta: PT. Pustaka Insan Madani

WHO. 2015. The World Health Report 2015. http://www.who.int/mediacentre/factshe et/fs351/en/ diakses : 12 Maret 2017, 16.30 WIB. 